\title{
UM CORPO, TRÊS REGISTROS: RSI. CONSIDERAÇÕES SOBRE O FENÔMENO PSICOSSOMÁTICO
}

Andréa Vilanova

Psicóloga, psicanalista; professora e supervisora do Curso de Especialização em Clínica Psicanalítica do Ipub; doutoranda em Psicologia Clínica / PUC-Rio.

RESUMO: Na psicanálise o corpo tem uma constituição muito precisa, avessa às coordenadas anatomofisiológicas. Trata-se de um corpo afetado pela linguagem. A incorporação da estrutura promove uma transcrição do corpo que não é sem resto. No fenômeno psicossomático verifica-se que o objeto a não cumpre seu destino de objeto perdido, mantendo-se encarnado. A operação analítica permite uma relocalização do gozo, restituindo ao corpo o vazio que o constitui ao conduzir o gozo às bordas corporais sob efeito da modulação significante, na fala.

Palavras-chave: Fala, corpo, gozo, objeto a, fenômeno psicossomático.

ABSTRACT: A body, three registers: RSI. Questions about the psychosomatic phenomenon. In psychoanalysis the body has a very precise constitution that differs from the medical concept. In psychoanalysis the body is affected by language. The incorporation of the language promotes a transcription of the body without leaving something behind. In the psychosomatic phenomenon, object a does not follow the destiny of a lost object, and remains incarcerated. The analytic operation allows a relocation of jouissance, restoring to the body the emptiness that fills it when leading jouissance towards the borders of the body under the effect of signifier modulation, through speech.

Keywords: Speech, body, jouissance, objet petit a, psychosomatic phenomenon. 
"A fala, com efeito, é um dom de linguagem, e a linguagem não é imaterial. É um corpo sutil, mas é corpo. As palavras são tiradas de todas as imagens corporais que cativam o sujeito; podem engravidar a histérica, identificar-se com 0 objeto do Penis-neid, representar a torrente de urina da ambição uretral, ou o excremento retido do gozo avarento." (LACAN, 1953, p.302)

\section{INTRODUÇÃO}

O texto em epígrafe demonstra a força da articulação do corpo com nossa condição de seres falantes. O que Lacan destaca desde o início de seu ensino é essa íntima articulação do corpo com a linguagem, cujos desdobramentos mais fundamentais podem ser localizados na década de 1970, a partir do Seminário Encore — em homofonia com “en corps”. É nesse seminário (1972-1973/1993) que o autor dará todo o peso à presença do corpo, enfatizando sua pertinência às formulações clínicas engendradas pelo axioma fundamental que instaura a linguagem como a estrutura à qual se está subordinado.

A perspectiva lacaniana estabelece uma dimensão de investigação clínica que extrapola as referências ao sintoma como mensagem, endereçamento. Trata-se de uma questão que será desdobrada até chegar à formulação do sintoma como acontecimento de corpo (LACAN, 1975-1976/2007). Ainda que a temática estivesse presente desde o início de seu ensino, Lacan (1972-1973/1993) abre uma via que desloca a clínica de suas coordenadas significantes para incluir a perspectiva daquilo que, não sendo propriamente do campo do sentido, não deixa de portar algo da potência do significante.

Como materialidade anatômica, o corpo inaugura para a ciência médica um novo campo de intervenção. A possibilidade de acesso ao cofre negro dos corpos, celebrada pela dissecação de cadáveres e postulada como método anatomopatológico por Bichat, no final do século XVIII (FOUCAULT, 1989), pôs em ato a divisão cartesiana: corpo (res extensa) corpo e pensamento (res cogitans).

Justamente porque cadaverizou o corpo, a medicina pôde operar. Uma dimensão totalmente nova oferece ao saber médico o brilho material de seu objeto. O substrato espacial passa a constituir o elemento estrutural do olhar científico que se erige no campo da medicina. Pode-se afirmar que há um universo entre a elementaridade da matéria anatômica e a riqueza da clínica. Algo escapa à abordagem balizada pelas coordenadas anatômicas fundantes da moderna clínica médica. ${ }^{1}$

\footnotetext{
1 Temática desenvolvida pela autora em sua dissertação de mestrado: "Do corpo finito ao infinito no corpo: considerações sobre a morte na Medicina e na Psicanálise”, Ipub/UFRJ, 2000.
} 
Ao cunhar a expressão corpsificar (de corpse, cadáver, em inglês), Lacan (1970/2003) evidencia a disjunção essencial com a perspectiva do cadaverizar inaugural do nascimento da clínica médica. Ainda que estas concepções guardem certa relação com a mortificação do organismo, a psicanálise, no entanto, evidencia que a mesma operação que mortifica a carne também vivifica o corpo. Lacan (1972-1973/1993) decompõe a ação do simbólico, e afirma que o significante é a causa material do gozo, ou seja, o índice de vida de um corpo.

Nomeado em suas partes e funções, o corpo advém como superfície de intervenção médica. Por um lado, medicina e psicanálise têm acesso ao corpo nomeado pelo significante, por outro, extraem-se daí consequências diversas. Fundamentalmente, podemos tomar o fato de que a psicanálise evidencia nisso que vivifica o corpo a causa de uma etiologia sexual, que de modo algum pode ser reduzida a uma etiologia biológica.

O acesso ao corpo não se restringe, portanto, à direção dada pelo discurso da ciência. Com Freud, subverte-se a anatomia e instaura-se outra rede de demarcações. É o que indicou ao considerar o corpo pela palavra, articulando-o como corpo libidinal. Lacan (1964/1988) propõe que a libido freudiana seja tida como um órgão incorporal que se volatiliza com o nascimento. Organismo e corpo estarão doravante irremediavelmente separados, diferenciados.

Na medicina, o que se convencionou chamar de 'psicossomática' surge como um elemento refugado que acompanha o avanço do discurso médico, afirma Valas (1987/2003). A categoria dos transtornos psicossomáticos está presente nos manuais como manifestações que, apesar de extensamente descritas na literatura médica, encontram na etiologia um ponto de impasse. Com quadros clínicos refratários às terapêuticas e intervenções, protocolares que pretendem incidir sobre o corpo apenas em sua materialidade orgânica, o fenômeno psicossomático convoca a inclusão do fator emocional. As manifestações psicossomáticas ocupam uma posição de borda frente ao saber médico.

Articulado contemporaneamente como 'estresse', o fator emocional é elevado à categoria de causa, ainda que não se saiba bem o que fazer com isso. A psicossomática constitui-se como um campo conceitual, no qual transitam médicos e psicólogos, cuja leitura da clínica deixa de lado o que há de radical na formulação da pulsão: o fato de não se tratar de algo que emana de um suposto ser primordial, ou do mais profundo do organismo. De fato, inclui-se em sua etiologia algo da ordem do psíquico, mas o que a psicanálise permite discernir é que corpo e psiquismo não constituem entidades disjuntas.

Nesta direção, nossa perspectiva de abordagem segue uma leitura do fenômeno psicossomático tomado como uma questão dentro do campo constituído pela referência fundamental à incorporação da linguagem. Trata-se de uma premissa que nos orienta na formulação de que corpo não se resume a uma evidência 
natural e observável. A pulsão inaugura um ponto de ruptura com as leituras psicologizantes frente a estas manifestações, e propõe uma outra direção que exige manobras teóricas e clínicas, fundamentadas no ensino de Freud e Lacan.

\section{QUE CORPO?}

O pensamento cartesiano, base filosófica para o nascimento da medicina moderna, tem na distinção corpo e mente uma disjunção que Lacan (1974-1975) subverterá ao interrogar o que faz de um corpo um corpo vivo. Afirma ainda que um corpo pode ser definido por funções especificadas em órgãos, mas isto não basta: “Um automóvel, ou mesmo um computador, segundo as últimas notícias, é também um corpo, mas não é óbvio, digamos, que um corpo seja vivo" (LACAN, 1974-1975, p.12).

O que designa a vida de um corpo está para além de suas funções e mecanismos descritos pelo discurso médico ao longo dos tempos. Há uma dimensão própria ao ser falante que introduz o que Lacan chama de certa debilidade; algo que interfere num pretenso funcionamento, regulado por um saber instintivo regido pelas leis da natureza. Como ponto de partida, subverte-se, a partir do conceito de pulsão, a disjunção que situaria o corpo dentro das coordenadas orgânicas e o psiquismo como campo mental, desvinculado do suporte material. O que a psicanálise estabelece como parâmetro de vida num corpo são os desvios inerentes à lógica da satisfação, os atropelos em que o sujeito se surpreende não sendo senhor em sua própria casa.

A linguagem introduz no ser que fala essa dimensão de ruptura com qualquer ideia de programação. Entre o psíquico e o somático, Freud introduz a pulsão. Poderíamos considerar que a dualidade cartesiana é substituída pela tensão lacaniana entre corpo e linguagem. Mas, já em Freud, podemos localizar as bases da subversão epistemológica operada pela psicanálise no campo da clínica, cujo eixo fundamental está em designar ao corpo um lugar na própria economia libidinal.

Freud estabelece uma teoria sobre o aparelho psíquico que se apoia, inicialmente, a partir de noções como tensão e descarga, numa regulação que tende a restaurar certa homeostase. Originalmente, define diferentes mecanismos psíquicos para lidar com as excitações: a conversão e o deslocamento. No entanto, o funcionamento psíquico ancora-se numa operação que não se detém apenas no trânsito de excitações entre o psíquico e o somático. A referência ao objeto, presente desde o Projeto, vai configurar um campo em que o próprio corpo se estabelece em nova perspectiva.

Segundo Freud (1917/1976), “A defecação proporciona a primeira oportunidade em que a criança deve decidir entre uma atitude narcísica e uma atitude de amor objetal” (p.163). Articulam-se aí a constituição do corpo e a constituição 
do campo do Outro, mediados pelo objeto. Mas, é a partir dos avanços frente à concepção do narcisismo que Freud (1917/1990) nos apresenta um funcionamento que parte de uma referência ao corpo enquanto objeto de investimento. A perspectiva de haver um 'dentro' separado de algo 'fora' se esmaece; a torção provocada pela perspectiva do sujeito tomar seu corpo como objeto de investimento reelabora a própria teoria.

Temos aqui a presença de elementos decisivos: o organismo como fonte de estímulos fundamentais à economia psíquica, transpostos em exigências pulsionais (FREUD, 1915/1990), necessariamente mediadas por certa dialética da constituição do objeto que resta da transposição, Entstellung. Marca-se a singularidade do que Freud propõe ao indicar, na articulação entre o somático e o psíquico, uma operação que se destaca como chave para a leitura da operação de incorporação da estrutura formalizada por Lacan (1970/2003).

Verificamos, com Lacan, que a primeira aparição do termo Entstellung ocorre em 1900, no texto $A$ interpretação dos sonhos, de Freud. Observa-se, a partir da leitura de Lacan (1957/1988), o que Freud destaca como precondição geral da função do sonho. Se, por um lado, Lacan destaca o deslizamento significante em ação no discurso, por outro, não deixa de situar o valor significante da imagem, articulado a uma não significação.

"Essa estrutura de linguagem que possibilita a operação da leitura está no princípio da significação do sonho, da Traumdeutung.

Freud exemplifica de todas as maneiras que esse valor de significante da imagem nada tem a ver com sua significação, e recorre aos hieróglifos do Egito, onde seria ridículo deduzir da frequência do abutre, que é um Aleph, ou do pintinho, que é um vau para assinalar uma forma do verbo ser e também os plurais, que o texto concerne minimamente a esses espécimes ornitológicos. Freud encontra meios de se orientar, nessa escrita, por certos empregos do significante [...]

A Entstellung, traduzida por transposição, onde Freud mostra a precondição geral da função do sonho, é o que designamos anteriormente, com Saussure, como o deslizamento do significado sob o significante, sempre em ação (inconsciente, note-se) no discurso." (LACAN, 1957/1988, p. 514)

Na operação de transposição, sempre em ação — destaca Lacan —, algo não pode ser assimilado à significação, o que podemos situar pela barra do algoritmo $\mathrm{S} / \mathrm{s}$, que inscreve a irredutibilidade em que se constituem as relações do significante com o significado, o ponto de resistência à significação. Algo resta e resiste à transcrição significante, mas nem por isso deixa de produzir seus efeitos. Aliás, sobretudo por isso produz seus efeitos. Esta perspectiva, presente em Freud, foi 
efetivamente desenvolvida por Lacan, com a introdução da concepção de um objeto que se define essencialmente como falta.

Apesar de ser possível uma leitura de referências anteriores de Freud acerca da perda do objeto tomada como função constitutiva, somente a partir de Inibição, sintoma e angústia (1925/1990) pode-se estabelecer a concepção de um objeto perdido desde sempre, e a relação essencial desta perda fundamental ao campo do Outro. O conceito de castração ganha aí sua radicalidade, situado num ponto anterior a qualquer experiência de perda objetal. Uma vez que "o perigo agora está internalizado” (LACAN 1954-1955/1985, p.151), a castração ganha uma localização estrutural.

Verifica-se um reordenamento fundamental que instaura novos parâmetros na relação ao objeto. Seria a elaboração de uma perda fundamental que constitui o próprio aparelho psíquico. Há, portanto, uma perda constitutiva na operação que inscreve o vivente, tendo como suporte o seu corpo, na relação ao Outro. Com Lacan, a referência de Freud ganha status de postulado e designa à ordem da linguagem o estatuto de alteridade fundamental. O acesso ao corpo só se dá pela imagem, que não pode ser considerada sem uma referência à estrutura da linguagem.

“Volto primeiro ao corpo do simbólico, que convém entender como nenhuma metáfora. Prova disso é que nada senão ele isola o corpo, a ser tomado no sentido ingênuo, isto é, aquele sobre o qual o ser que nele se apoia não sabe que é linguagem que lho confere, a tal ponto que ele não existiria, se não pudesse falar. O primeiro corpo faz o segundo, por se incorporar nele.” (LACAN, 1970/2003, p.406)

Capturado pela estrutura da linguagem, o vivente experimenta uma perda constitutiva em sua relação ao objeto, evidenciada por Freud em suas versões do objeto perdido — seio, fezes, falo — , e formalizada por Lacan com o objeto a. Além de acrescentar voz e olhar a esta série, atestou ao umbigo do sonho freudiano o estatuto do "centro incógnito, que não é mesmo outra coisa, como o próprio umbigo anatômico que o representa, senão esta hiância da qual falamos” (LACAN, 1964/1988, p.28).

De que corpo falamos, quando abordamos o corpo definido pela psicanálise? Freud e Lacan nos indicam coordenadas essenciais que merecem destaque. Freud (1914/1990) expõe a paixão humana pela imagem narcísica, não deixando de destacar o apoio que esta imagem encontra no corpo: "O eu é antes de tudo um eu corporal” (FREUD, 1923/1990, p.238). Numa primeira abordagem do corpo, Lacan (1949/1998) destaca o fato de que se introduz na economia do gozo pela imagem a assunção jubilatória. Articula à imagem a prematuração biológica da criança capturada no espelho do Outro, e destaca a função identificatória colo- 
cada na base da "transformação produzida no sujeito quando ele se assume uma imagem” (LACAN, 1949/1998, p.97),

“apanhado no engodo da identificação espacial, as fantasias que se sucedem desde uma imagem despedaçada do corpo até uma forma de sua totalidade que chamaremos de ortopédica [...] uma identidade alienante que marcará com sua estrutura rígida todo o seu desenvolvimento mental”. (LACAN, 1949/1998, p.100)

Verificamos que a unidade corporal não é um fenômeno anatômico. Não há correspondência com o real anatomofisiológico. Com Lacan, evidencia-se a função de captura que a imagem especular exerce e as consequências do fato de que só se tem acesso ao corpo pela sua forma imaginária. Podemos verificar que o corpo é necessariamente definido em relação à falta, seja pela leitura da falta inscrita pelo significante ao fazer furo no real do organismo, seja pela imagem do corpo que inscreverá uma dessemelhança em relação ao próprio sujeito.

Verificamos no ensino de Lacan, partindo do Estádio do espelho, uma absorção progressiva da imagem na função significante (Idem), o que leva à radicalização da relação do significante com o corpo. Se, por um lado, podemos discernir o gozo vinculado ao júbilo da imagem no espelho, por outro, temos uma operação contígua, que inscreve na carne as marcas que serão significadas a posteriori pelo sujeito: "a relação especular vem a tomar seu lugar e a depender do fato de que o sujeito se constitui no lugar do Outro, e de que sua marca se constitui na relação com o significante" (LACAN, 1962-63/2005, p.41). Declinam-se dimensões do gozo, cujo discernimento orienta nossa interrogação sobre o que se passa no fenômeno psicossomático.

Uma vez que a imagem do corpo é o suporte da relação do sujeito ao desejo do Outro, precisa-se destacar aqui a função que sustenta esta imagem. No fundo da imagem especular há este objeto que escapa ao sujeito, ao mesmo tempo em que o constitui. Trata-se da imagem do corpo próprio, metaforizada pelo corpo especular como vestimenta do objeto a. Lacan (1960/1998) afirma que "é a este objeto inapreensível pelo espelho que a imagem especular fornece a vestimenta" (p.818). É nesta conjugação que podemos identificar a tensão entre a dimensão especular, imaginária, e a dimensão escópica, o plano real do objeto da pulsão, ambas fundadas sob a condição de falante a que se está submetido. Neste sentido, o objeto a é aquilo que sustenta a imagem especular, exatamente por furtar-se a ela.

"É preciso insistir sobre esta inversão de peso: o furo não é definido pela superfície, ele a define. O furo não está no real do corpo, transmitido por contiguidade aos buracos negros em sua imagem. O corpo não existe per se, tendo áreas cheias 
que definem, em suas ausências, orifícios. O corpo agora se define pelo fato de ter furos e de nestes furos concentrar-se o gozo [...] Podemos dizer até que o corpo é o que existe em torno do objeto, desde que se entenda aí por objeto o objeto a de Lacan.” (VIERA, 1999, p.50)

Trata-se aqui do objeto a em sua radical ex-sistência, que permite à consistência corporal constituir-se dentro das coordenadas de sua estrutura tórica. O corpo é condição da presença do sujeito no mundo, mas não apenas isso, já que não nos é dado pura e simplesmente pelo espelho. Assim, um vazio central marca a experiência com o corpo próprio, que é o lugar de uma perda irremediável que nenhum objeto pode restaurar. Esta perda é a causa da atividade central do corpo, para além de qualquer referência a uma autoconservação. A formalização do conceito de real possibilita a articulação ímpar da experiência corporal na clínica.

Há, portanto, um resto que escapa ao estatuto da imagem especular, que pode ser definido como o próprio objeto a, o objeto que marca a disjunção entre corpo e organismo e define um lugar estrutural para a falta. Uma falta que se declina num extra-corpo, condição para a própria constituição do corpo (RECALCATI, 2003). O corpo, observado a partir das zonas erógenas num traçado da pulsão desenhado pelos objetos naturais, é regulado por um gozo que desliza para fora, onde o objeto advém como o elemento que guarda algo do corpo vivo, ao mesmo tempo em que dele prescinde para sustentar a realidade do sujeito, como furo. Isto permite pensar que este objeto possa ser substituído por outros, de toda ordem, encarnando-se nos objetos da cultura.

Na tematização do corpo está em jogo uma extimidade fundamental, que pode ser lida na relação do sujeito com o objeto de sua satisfação, definido necessariamente como inexistente, que, no entanto, pode ser localizado na troca de olhares, à margem, a partir de coordenadas estabelecidas pela amarração das três instâncias que o compõem: real, simbólico e imaginário. A carne golpeada pelo significante produz a separação entre corpo e gozo. E o elemento incorporal, um nome para o real da pulsão freudiana, faz eco no corpo, um corpo parcial, na medida que não se ‘é’ e não se ‘tem’ um corpo, como nos ensina Lacan.

No final de seu ensino, Lacan dá ao corpo a dimensão de sua radicalidade: "um corpo é algo que está feito para gozar, gozar de si mesmo” (LACAN 1966/185, p.92). O descentramento instaurado pela incorporação da estrutura da linguagem determina uma alteridade que se assenta num arrebatamento do sujeito, exilado de um corpo natural, capturado na miragem do espelho, mortificado pelo que o nomeia e vivificado pelas marcas significantes que o inscrevem na economia libidinal. 
O corpo está enraizado no imaginário, como testemunha a montagem lacaniana. Aparece uno, mas isto não faz identidade. A própria imagem que o fixa inscreverá uma dessemelhança, que impede o sujeito de tomá-lo como corpo próprio. Há um corpo reunido ao redor dos feixes pulsionais, mas o sujeito não pode designá-lo como seu, e ao qual não pode identificar-se sem que se instaure em seu coração a dimensão de perda que o inscreverá como traço.

Na mesma medida que o corpo está submetido à linguagem, articula-se como forma, como imagem do corpo. São operações contíguas referidas ao efeito de perda instaurado pela inscrição do significante em sua vertente letra, que não comporta uma leitura em torno do sentido. A palavra logifica a carne pela inscrição do traço, das marcas que fundam um corpo para um sujeito que terá de encontrar seu jeito de habitá-lo.

O corpo não pode ser pensado em um espaço real. Delimita-se como uma construção puramente verbal, soletrada em três dimensões, não sem a inscrição do objeto a, cuja função vincula-se ao fato de que "o objeto é ob, obstáculo à expansão do imaginário concêntrico, isto é englobante” (LACAN, 1975-76, p.83). Objeto cuja propriedade fundamental é fazer consistir um ponto cego nesta arquitetura, o que nos permite conceber o ser falante entre o corporal e o incorporal, o humano e o inumano, o finito e o infinito.

\section{O FENÔMENO PSICOSSOMÁTICO (FPS)}

Podemos afirmar que o FPS compreende a manifestação de afecções somáticas, nas quais a presença da lesão — histopatologicamente objetivável — não permite um enquadramento pelo protocolo médico. Há um impasse imposto por uma etiologia inconsistente que escapa ao método de investigação da medicina, o que leva a adjetivar estas manifestações como idiopáticas (do grego idiopatheia, idios: pessoal, próprio; patheia: sensação, sofrimento), ou seja, permite defini-las como manifestações de um sofrimento singular, próprio a alguém.

De uma doença de etiologia desconhecida a uma forma de sofrimento própria a cada sujeito, o FPS encontra uma possibilidade de leitura dentro das coordenadas do método psicanalítico, que tem no encontro com o vivo, a cada caso, sua sustentação. Eis o princípio do método em Freud: que se sustenta no singular, na escuta de um sujeito, a cada vez, a cada caso.

De que se trata, quando se fala da presença de uma lesão marcada na carne, sensível à palavra, que se mobiliza em função de datas, aniversários? Como destaca Lacan, são:

“[...] fenômenos estruturados de modo bem diferente do que se passa nas neuroses, a saber, onde há não sei que impressão ou inscrição direta de uma característica e 
mesmo, em certos casos, de um conflito, no que se pode chamar o quadro material que apresenta o sujeito enquanto ser corpóreo." (1955-56/1997, p.352)

Cerca de 20 anos depois, Lacan (1975/1988) retoma a questão e novamente apresenta a lesão pela perspectiva de uma inscrição significante direta, na carne. Indica encontrar-se aí um curto-circuito no simbólico, onde a função da metáfora falha. Do ponto de vista clínico, podem-se distinguir reações psicossomáticas transitórias, ou a presença do fenômeno psicossomático como um modo de resposta permanente do sujeito. Podemos, ainda, identificar sua manifestação nas diferentes estruturas clínicas. Uma pluralidade que interroga o diagnóstico de estrutura pautado pela distinção entre neurose, psicose e perversão.

Valendo-nos das formulações conceituais edificadas ao longo de seu ensino, que põem o gozo, com suas modalidades de satisfação, no centro de suas elaborações, procuraremos situar com Lacan as coordenadas do que se revela como o núcleo de gozo, ponto de opacidade, avesso a uma direção do tratamento pela via da decifração significante. Um paradigma que introduz a dimensão do escrito (LACAN, 1972-73/1985), perspectiva presente na abordagem do fenômeno psicossomático, sobre o qual Lacan (1975/1988) afirma: "Finalmente, é de todos os modos da ordem do escrito. Em muitos casos, não sabemos lê-lo” (p.137).

O que o fenômeno em questão evidencia é que a incorporação da estrutura se faz por meio de uma operação de captura pelo simbólico, com uma necessária produção de gozo fora do simbólico, mas não fora de alguma referência ao significante, em sua vertente letra, que introduz a dimensão do escrito. A escrita não é de modo algum da mesma cepa que o significante. O importante é saber o que, num discurso, se produz por efeito de escrita (LACAN, 1972-73).

“[...] aquilo de que se trata em Freud, que é efetivamente um saber, mas um saber que não comporta o menor conhecimento, já que está inscrito num discurso do qual a semelhança do grilhão de antigo uso, o sujeito que traz sob sua cabeleira o codicilo que o condena à morte não sabe nem o sentido nem o texto, nem em que língua ele está escrito, nem tampouco que foi tatuado em sua cabeça raspada enquanto ele dormia." (LACAN, 1960/1998, p.818)

O corpo advém como campo de inscrição da letra, cifra deste gozo do Outro, em que se exibe a marca, suporte de um gozo específico. É nos desarranjos do corpo erógeno, corpo pulsional, não assimilável nem a um corpo biológico, nem a um corpo simbólico, onde podemos situar o fenômeno psicossomático. E o que este fenômeno demonstra é a radicalidade da articulação daquilo que se encontra fora do sentido, mas não fora do simbólico, com o corpo. Trata-se de uma dimensão real inerente ao significante, no ponto em que não há propria- 
mente um significante, mas uma inscrição primeira, um hieróglifo no deserto, como indicou Lacan.

Ao situarmos a lesão como um sem sentido impresso no corpo, não se propõe que a interroguemos, mas de localizar, a partir dos casos, os efeitos que a passagem da leitura do sintoma como metáfora para o sintoma como acontecimento de corpo produzem na leitura da clínica. Verificamos, ainda na indicação de Lacan (1975/1988), que a dimensão do escrito engendra algo da ordem do número, da contagem, articulando o gozo à metonímia. A questão parece estar, portanto, do lado do objeto da pulsão em sua relação com o significante isolado, e não do lado da cadeia significante.

Na mesma conferência, Lacan aponta que, em presença da lesão nos fenômenos psicossomáticos, somos confrontados com o que chama de "gozo específico que há em sua fixação” (p.139). Miller (1989) afirma que nesses casos estamos diante de uma corporificação da libido, como resultado não da incorporação da estrutura, mas da incorporação de um significante na forma de certo imprimatur, certa fixação. Deve-se, portanto, considerar o fenômeno psicossomático pelo gozo específico e interrogar o estatuto desta fixação, articulado à pregnância da consistência imaginária.

Miller (1988/2003) é categórico ao afirmar que o fenômeno psicossomático “existe em sua consistência como diferente do sintoma, pelo fato dessa diferença situar-se nos limites da estrutura da linguagem” (p.174). A sua proposição nos coloca diante da necessária abordagem dos elementos que a compõem: linguagem e consistência. Considerando-os como elementos de um binômio que permite vislumbrar elementos que se conjugam no corpo, somos convocados a incluir o que faz acordo entre estes termos. Paradoxalmente, o que faz acordo é o que se mantém em exclusão, o que constitui o eixo fundamental da própria possibilidade de sentirmos o corpo como tal. Desse modo, aqui, teríamos o objeto a em sua radical ex-sistência, que permite à consistência corporal sua precariedade constitutiva.

Consideramos que o FPS refere-se a uma construção do corpo aderida à consistência imaginária, um corpo declinado "segundo as leis da chamada geometria, e que são aquelas do balão ou da bola, imaginado cinestesicamente, isto é, oral-analmente” (LACAN, 1975-76, p.83). No fenômeno psicossomático, tomamos o corpo como uma superfície na qual se escreve uma modalidade de resposta do sujeito ao Outro, à inconsistência do Outro.

No final do ensino de Lacan, a temática da inconsistência do Outro é tida como estrutural para o ser falante. A dimensão de déficit simbólico deixa de ser um traço clínico exclusivo da psicose, pois ganha uma perspectiva mais abrangente no quadro da experiência fundamental daqueles que habitam a linguagem. Skriabine (1994) aponta que à generalização da inconsistência do Outro cor- 
responde uma generalização da ideia de suplência, como uma pluralização dos Nomes-do-Pai. Gorostiza (2003) retoma Miller e afirma que o próprio sintoma é o que vem no lugar da programação natural que não existe, vem fazer suplência à não-relação. Ao mesmo tempo em que advém como uma solução, o sintoma também é índice do que não anda.

Partindo do princípio de que o FPS seria uma manifestação que interroga a própria clínica psicanalítica erguida por Freud em torno do desejo inconsciente, da transferência, do recalque, do sintoma e das formações do inconsciente, nos deparamos com a exigência epistemológica que levou Lacan a elaborar a articulação entre corpo e linguagem, destacando o caráter real do objeto a. Entre corpo e linguagem, é o real que faz acordo (LACAN, 1975-1976/2007). E é aí que se inscreve o sintoma, definido como um fenômeno que articula, desde Freud, a dimensão de mensagem, sua vertente significante e a do trauma sexual, como o ponto impossível de significar.

Lacan (1964/1988) considera o sujeito como inscrição de uma afanisis, termo extraído por ele de Ernest Jones, que o articulou em termos de castração. Para Lacan, o sujeito se inscreveria, no intervalo da cadeia significante $\left(\mathrm{S}_{1}-\mathrm{S}_{2}\right)$, como intervalo, furo estrutural. Aqui, o FPS é colocado em série, com manifestações clínicas caracterizadas por uma solda significante, a holófrase, na qual o sujeito parece ausente da enunciação e a dimensão do sintoma como mensagem endereçada não se apresenta.

As formulações em torno do método freudiano, situado sob a perspectiva da decifração, oferecem as coordenadas para nossa ação frente ao sujeito que, por sua própria vontade, se apresenta com sua divisão; mostram-se, entretanto, insuficientes para abordar aqueles que, em geral, chegam a um encontro forçado com o analista, seja numa instituição, seja no consultório, a partir de uma prescrição médica, entre tantas outras.

O FPS pode ser considerado, a partir dos pressupostos de Freud e Lacan em torno da incorporação significante, como uma manifestação que ultrapassa os limites de uma clínica estrutural. Caracterizando-se mais como uma resposta do que como um enigma, faz obstáculo à perspectiva de elaboração de uma demanda ao Outro e traz interrogações sobre a direção do tratamento. Ele advém como um negativo da operação de extração do objeto, concernente à operação de incorporação da estrutura.

Verificamos que a produção de um corpo, dentro das coordenadas orientadas por Freud e Lacan, encontra-se no limite de sua consistência, instalada sobre a marca de um vazio constitutivo, numa articulação que se sustenta no caráter de mortificação do corpo como efeito da incorporação simbólica, e assevera ao produto desta operação — o objeto a — a função de mobilizar a única substância que consiste, para o sujeito, seu gozo. O que faz de um corpo um corpo vivo 
põe em jogo a dialética sujeito-objeto, com todas as suas consequências para a realidade de um sujeito.

O postulado freudiano da sobredeterminação inconsciente encontra em Lacan, no final de seu ensino, a possibilidade de abarcar aquilo que parece escapar ao axioma do inconsciente estruturado como linguagem. É a construção de um saber possível sobre as formas de satisfação de um sujeito, quer sejam cifradas através do sintoma, quer sejam escritas no corpo, como ocorre no FPS, já que haverá sempre um ponto avesso à possibilidade de ciframento e, portanto, de decifração pela via do significante. Lacan (1975/1988) afirma que é pela revelação do gozo específico que há em sua fixação que se deve abordar o psicossomático, ao que acrescentaríamos que se trata de abordar o doente e não o fenômeno, o que, apesar de parecer óbvio, vale destacar.

Verifica-se que a operação fundamental de incorporação da estrutura separa gozo e corpo. Com o FPS, constata-se que esta operação não é cronológica, mas lógica, dados os efeitos do tratamento analítico sobre estas manifestações sensíveis ao tratamento pela palavra. Não se deve, pois, considerar uma incorporação gradual da estrutura da linguagem, na perspectiva de um desenvolvimento. Há um antes, sobre o qual nada sabemos, e um depois, que manifesta essa desnaturalização do corpo.

Miller (2003/2006) destaca que o que chamamos ordem simbólica é em si mesma um nada: “na ordem simbólica não há nada. Esta ordem se mantém muito bem como hieróglifo no deserto sem nada que o leia e permanece, conserva sua consistência” (p.376). Disto depreende-se que o sujeito do significante feito de lógica pura está fora da vida. O que vai designar que há alguém são os signos de gozo do sujeito. "E na psicanálise não se discute reduzir o analisante ao sujeito do significante, uma vez que se é coerente com esta disposição; ali há alguém” (MILLER, 2003/2006, p.376).

Verificamos que no FPS o gozo não obedece à regulação que promove a disjunção do corpo com o gozo. Daí advém toda a problemática relativa ao gozo específico que atesta algo semelhante a uma encarnação do objeto no corpo. O FPS confronta o dispositivo analítico pela presença do corpo em primeiro plano, o que exige do analista um redimensionamento de sua tática. Isto é algo que já está proposto por Lacan ao situar, no final de seu ensino, o núcleo de gozo no coração do sintoma freudiano, com a postulação do sinthome, que se definiria pela conjugação do sujeito com o gozo.

Diante desses casos, fica evidente que algo escapa às coordenadas da lógica do gozo domesticado pelo significante. Como abordá-lo, senão pela palavra? É assim que S chega ao encontro com um analista, após longo período de tratamento médico e psicológico de uma “doença intestinal inflamatória”, "uma irritação no cólon”. Seu quadro clínico, progressivamente agravado por crises, resultou 
em uma intervenção radical: "perdi meu intestino”. Entre acusações e queixas, convidada, pôs-se a falar.

Em seu ensino, Lacan (1975/1988) propõe que a abordagem do FPS encontra a formulação de um enlace do gozo de um corpo vivo com o traço mais elementar do significante. Uma articulação que permitirá situar esse fenômeno para além de supostos saberes (lúpus, doença de Crohn, vitiligo, psoríase etc.), tornando possível articulá-lo à modalidade de satisfação de cada sujeito. Não é o caso de se considerar o FPS como portador de um saber prévio. Interessa o que cada sujeito vai fazer com isso. Esta posição ética convida a levar a sério o fato de que o paciente fala, e que há um descompasso entre seu dito e a enunciação de seu discurso. Sobretudo, a experiência da psicanálise atesta que não há significação última válida para todos.

O inconsciente estruturado como linguagem, formulado por Lacan, introduz o corte necessário à assunção do inconsciente como um operador, e não como um depósito de lembranças censuradas. Verificamos que, em Freud, a definição de inconsciente articula-se à concepção de uma memória que não é passível de plena recordação, o que é representado pelo umbigo do sonho que ex-siste ao próprio sonho. Mas, a este furo vem fazer borda o próprio inconsciente como esquecimento, apagamento dos traços, como podemos considerar desde o protótipo do inconsciente freudiano do Projeto, com a experiência de satisfação primária pela alucinação do seio, na qual a representação vem a ser aquilo que da pulsão é possível ter acesso.

Lacan afirma, dentre as poucas passagens sobre o tema ao longo de seu ensino, que no FPS algo parece escrito no corpo. Miller (1989/2003) avança e indica que se verifica no FPS que um órgão, ou uma parte do corpo, toma nota do que sucedeu como evento traumático. Parece, portanto, um curto-circuito que se interpõe à própria possibilidade de inscrição do inconsciente como memória. Só temos o testemunho mudo da lesão, pois o corpo não está submetido à transposição que inscreveria o próprio corpo como traço, permitindo o advento do sujeito. Da lesão, marca, que por não estar perdida, metaforizada, se instala como “memória do real” (ARAMBURU, 1999, p.176) na carne, é preciso passar à Outra cena que, circunscrevendo algo da fantasia do sujeito, introduza a dimensão da ficção, permitindo deslocar a fixação de gozo.

Considerando a indicação do que Lacan situa ao final de seu ensino, segundo Miller (1986/2003), o inconsciente advém como aquilo que se escreve nas marcas de gozo deixadas pelo encontro com o próprio significante. No FPS, parece que estamos diante de um fenômeno que evidencia um obstáculo que se interpõe à própria possibilidade de inscrição dessa memória. Obstáculos à parte, para que o inconsciente exista é preciso que seja escutado, nos ensina Lacan. Uma advertência que aponta uma direção clínica. 
Miller (1998/2006) afirma que a interpretação ganha o status de leitura, que se refere à apreensão do cifrado fora de sentido, fora da significação e, portanto, fora de toda compreensão, de toda comunicação. Ou seja, dar o salto que compreende tomar o corpo pelos signos de gozo, de um corpo afetado pelo gozo, em seus efeitos subjetivos, e não signos da vida de um corpo, ainda que não haja gozo sem vida. O discurso psicanalítico encontra-se sobre o ponto preciso em que quando não há "nada a dizer” é que é preciso falar, a fim de possibilitar ao sujeito rearticular saber e gozo e continuar escrevendo sua história.

Lacan (1953/1998) aponta a morte "não como término eventual da vida do indivíduo, nem como certeza empírica do sujeito, mas, segundo a fórmula que dela fornece Heidegger, como "possibilidade absolutamente própria, incondicional, insuperável, certeira e, como tal, indeterminada do sujeito’” (p.319). Todo o apelo de gravidade do diagnóstico médico, repleto de sentido, não é suficiente para produzir uma mudança de posição. O que permite a $\mathrm{S}$ deixar de gravitar em torno do objeto encarnado?

S traz uma cena: sentada no colo de seu pai, enquanto este corta a carne em seu prato e lhe dá comida na boca. " [...] fiquei mocinha ele mudou comigo [...] perdi o colo do meu pai”. A cena fantasmática — com o que possa comportar do real do gozo - advém na cena analítica, remetendo à Outra cena. Cativar no sujeito a modulação do significante pela palavra, na fala, permitiu que o objeto revestido de intestino perdido ganhasse contornos de objeto perdido, articulado a partir de uma transcrição simbólica que permitiu a extração lógica do objeto no curso do tratamento.

É um novo arranjo que restitui ao significante sua potência de fazer furo no real do corpo, em que o objeto vai se sustentar como objeto a, causa de desejo. Verificamos ser esta uma nova maneira de traçar o circuito da pulsão, restituindo ao corpo o vazio que o condiciona e relocalizando o gozo em suas bordas. Uma operação que se faz sob transferência. Pois, na clínica dos fenômenos psicossomáticos, como propõe Alain Merlet, trata-se "de fazer passar uma resposta muda a uma pergunta articulada com o objetivo de produzir uma variável que é o sujeito, para que possa tomar o lugar no dispositivo, se o consentir" (1999, p.138).

Recebido em 25/7/2008. Aprovado em 30/10/2008. 


\section{REFERÊNCIĀS}

ARAMBURU, J. (1999) “El FPS y la clínica borromeana”, in GORALI, V. Estudios de psicosomatica, v. IV, Buenos Aires: Atuel-Cap, p.173-179.

FREUD, S. (1970/1987) Edição standard brasileira das obras psicológicas completas de Sigmund Freud. Rio de Janeiro: Imago.

(1900 /1987) “A interpretação dos sonhos", v. IV e V.

(1910/1970) "A concepção psicanalítica da perturbação psicogênica da visão”, v. XI, p.193-203.

(1914/1974) "Sobre o narcisismo: uma introdução”, v. XIV, p.85119.

(1915/194) “As pulsões e seus destinos.” v. XIV, p.129-162.

(1917/1976) As transformações do instinto exemplificadas no erotismo anal”, v. XVII, p.157-166.

(1920/1976) “Além do princípio do prazer." v. XVIII, p.13-90.

(1926/1976) "Inibições, sintoma e ansiedade." v. XX , p.95-201.

(1950 [1895]/1977) "Projeto para uma psicologia científica”, v. I.

GOROSTIZA, L. (2006) A nobreza do sintoma, in Latusa digital, ano 3, n.21, março.

LACAN, J. (1966/1985) "Psicoanalisis y medicina”, in Intervenciones y textos 1, Buenos Aires: Manantial.

. (1975/1988) "Conferencia em Genebra”, in Intervenciones y textos 2, Buenos Aires: Manantial.

. (1949 [1966]/1998) “O estádio do espelho”, in Escritos. Rio de Janeiro: Jorge Zahar.

(1953) "Função e campo da fala e da linguagem em psicanálise", in Escritos. Rio de Janeiro: Jorge Zahar.

(1957) "A instância da letra no inconsciente ou a razão desde Freud”, in Escritos. Rio de Janeiro: Jorge Zahar.

. (1970/2003) "Radiofonia", in Outros escritos. Rio de Janeiro: Jorge Zahar.

(1954-1955/1985) O Seminário Livro 2, O eu na teoria e na técnica psicanalíticas. Rio de Janeiro: Jorge Zahar.

(1962-1963/2005) O Seminário Livro 10, Angústia. Rio de Janeiro: Jorge Zahar.

(1964/1988) O Seminário Livro 11, Os quatro conceitos fundamentais.

Rio de Janeiro: Jorge Zahar.

(1972-1973 / 1993) O Seminário Livro 20, Mais ainda. Rio de Janeiro: Jorge Zahar.

(1974-1975) O Seminário Livro 22, RSI. Inédito.

(1975-1976 / 2007) O Seminário, livro 23, O sinthoma. Rio de Janeiro: Jorge Zahar.

MERLET, A. (1999) "Cambiar de escritura", in GORALI, V. Estudios de psicosomatica, v. IV, Buenos Aires: Atuel-Cap, p.137-147.

MILLER, J-A. (1989) “Algumas considerações sobre o fenômeno psicossomático”, in WARTEL, R. (org) (2003) Psicossomática e psicanálise. Rio de Janeiro: Jorge Zahar. 
(1998/2006) Los signos del goce . Buenos Aires: Paidós.

(2003/2006) La experiência de lo Real em la cura psicoanalítica. Buenos Aires: Paidós.

RECALCATI, M. (2003) Clínica del vacío. Madrid: Síntesis.

SKRIABINE, P. (1994) “La clínica del nudo borromeo”, in Locura: clínica y suplencia, Madrid: Eolia-Dor.

Andréa Vilanova

anvnova@gmail.com 